\title{
Clinical characteristics of refractory mycoplasma pneumoniae pneumonia in children treated with glucocorticoid pulse therapy
}

Zhenli Zhu ${ }^{1 \dagger}$, Tongqiang Zhang ${ }^{2,3 \dagger}$, Wei Guo ${ }^{4}$, Yaoyao Ling ${ }^{1}$, Jiao Tian ${ }^{1}$ and Yongsheng $X u^{4^{*}}$ (D)

\begin{abstract}
Background: To observe the effect of corticosteroids in the treatment of children with refractory Mycoplasma pneumoniae pneumonia (RMPP) under different doses, to summarize the clinical features of children treated with glucocorticoid pulse therapy.

Methods: The clinical data of 125 children with RMPP hospitalized in Tianjin Children's Hospital from September 2018 to October 2019 were retrospectively analyzed. They were divided into two groups according to the dose of hormone. Compare the clinical features, laboratory findings, and imaging between the two groups, and use meaningful related indicators as ROC curves to find reference indicators for pulse therapy.

Results: (1) The median age of the group II was older than that of the group I $(P<0.05)$. (2) We found more severe presentations, higher incidence of extra-pulmonary complications and more serious radiological findings in group II, which needed oxygen more often, higher the hormone, higher usage rate of gamma globulin, higher usage rate of bronchoscopy, and higher incidence of plastic bronchitis(P<0.05). (3) WBC, CRP, LDH, FER, D-D dimer, APTT, $T$, $P C T$, IL-6 and the percentage of neutrophils in peripheral blood in Group II were higher than those in Group II $P<$ 0.05). (4) In ROC curve analysis, CRP, LDH, FER, and neutrophils of leukocyte classification were independent related factors that could be used as valuable predictors of methylprednisolone pulse therapy for RMPP in children. The cut-off values were CRP44.45 mg/L, LDH590IU/L, FER411ng/L, and neutrophils in leukocyte classification were 73.75\%, respectively.
\end{abstract}

Conclusion: $C R P \geq 44.45 \mathrm{mg} / \mathrm{L}, \mathrm{LDH} \geq 590 \mathrm{IU} / \mathrm{L}, \mathrm{FER} \geq 411 \mathrm{ng} / \mathrm{L}$, neutrophil $\geq 73.75 \%$, lung consolidation, and pleural effusion may be predictors that guide the treatment of RMPP with pulse dose of GC.

Keywords: Mycoplasma pneumoniae pneumonia, Children, Glucocorticoid

\footnotetext{
*Correspondence: 1139350425@qq.com; drxu69@gmail.com

${ }^{\dagger}$ Zhenli Zhu and Tonggiang Zhang contributed equally to this work.

${ }^{4}$ Department of Respiratory, The Children's Hospital of Tianjin (Children's Hospital of Tianjin University), Tianjin 300074, China

Full list of author information is available at the end of the article
}

(c) The Author(s). 2021 Open Access This article is licensed under a Creative Commons Attribution 4.0 International License, which permits use, sharing, adaptation, distribution and reproduction in any medium or format, as long as you give appropriate credit to the original author(s) and the source, provide a link to the Creative Commons licence, and indicate if changes were made. The images or other third party material in this article are included in the article's Creative Commons licence, unless indicated otherwise in a credit line to the material. If material is not included in the article's Creative Commons licence and your intended use is not permitted by statutory regulation or exceeds the permitted use, you will need to obtain permission directly from the copyright holder. To view a copy of this licence, visit http://creativecommons.org/licenses/by/4.0/ The Creative Commons Public Domain Dedication waiver (http://creativecommons.org/publicdomain/zero/1.0/) applies to the data made available in this article, unless otherwise stated in a credit line to the data. 


\section{Background}

Mycoplasma pneumoniae (MP) is the main pathogens of community-acquired pneumonia (CAP) in children [1]. Mycoplasma pneumoniae pneumonia (MPP) is considered as a benign and self-limiting disease. However, it has been found that some children may progress to refractory Mycoplasma pneumoniae pneumonia (RMPP) after being treated with sufficient and long-term macrolide antibiotics in timely [2], which often leads to pulmonary necrosis and pleural effusion, which may not only be difficult to treat and costing, but also leave sequelae such as bronchiectasis, necrotizing pneumonia, bronchiolitis obliteransa and so on [3-7], thus affect the quality of life. Over-immune response of host plays an important role in the development of RMPP $[8,9]$. Studies have confirmed the effectiveness of glucocorticoid (GC) in the treatment of RMPP $[2,10,11]$. GC are effective in the treatment of severe RMPP by downregulating the cell-mediated immune response associated with lung injury during infection [12-15]. Therefore, on the basis of adequate anti-infective treatment, GC has attracted more and more attention [16, 17]. It is vital for clinicians to identify severe RMPP as early as possible and give pulse dose of hormone therapy. So, retrospective analysis was performed on 125 children with RMPP hospitalized in our hospital from September 2018 to October 2019. The purpose of this study was to compare the differences of clinical manifestations, laboratory data and imaging findings between two groups and to explore the predictive values of pulse therapy of RMPP.

\section{Methods}

\section{Patients}

This study selected 125 children with RMPP who were treated with different doses of GC at Tianjin Children's Hospital from September 2018 to October 2019. All children meet the diagnostic criteria of MPP $[18,19]$ : (1) Symptoms and signs of pneumonia showed on admission, including fever, cough, abnormal lung auscultation and so on; (2) Chest imaging indicated pneumonia; (3) Positive results of serologic test. Included patients underwent anti-MP IgM titrations twice, both at the time of admission and upon discharge. Patients who showed either a seroconversion (negative to positive), or four-fold or greater increase in IgM titers and who had both symptoms with $\geq 1: 640$ high titers [18]. RMPP was defined as a case with persistent fever, clinical and radiological deterioration after appropriate management with azithromycin for 7 days or more [2, 20]. Clinical and radiological deterioration were described as follows $[10$, 17]: aggravation of clinical signs was characterized by persistent fever, severe cough, dyspnea, etc. Radiological aggravation showed enlargement of pulmonary lesions, increased density, pleural effusion, and even necrotizing pneumonia and lung abscess.

The included had the following characteristics $[19,21]$ : (1) Meet the diagnostic criteria of MPP; (2) Meet the definition of RMPP; (3) Age $\leq 16$ years old. The exclusion criteria included any of the following [19, 21]: (1) Patients who had a history of tuberculosis, bronchiectasis, or lung tumors; (2) Patients who had diseases such as severe malnutrition, unconsciousness, chronic cardiac and pulmonary disease, congenital disease or immunodeficiency; (3) Patients who received GC before admission; (4) Patients who were discharged within $8 \mathrm{~h}$ after admission.

\section{Study design}

The 125 children were divided into two groups. Group I was given conventional dose methylprednisolone $2 \mathrm{mg} / \mathrm{kg} /$ day $(<200 \mathrm{mg} /$ day $)(n=81)$, and group II was treated with methylprednisolone pulse therapy $\geq 200 \mathrm{mg} / \operatorname{day}(n=44)$.

This study was approved by the ethics committee of the Tianjin Children's Hospital (Approved No. of ethic committee: L2021-01). The ethics committee waived the need for written informed consent provided by participants due to the retrospective nature of the study, because all patient data were analyzed anonymously, and no additional informed consent was required.

\section{Hormone grouping [22-24]}

Conventional dose was defined as intravenous infusion of methylprednisolone $2 \mathrm{mg} / \mathrm{kg} /$ day $(<200 \mathrm{mg} /$ day) (or an equivalent dose of dexamethasone, hydrocortisone, prednisolone or betamethasone), and pulse therapy $\geq 200 \mathrm{mg} /$ day methylprednisolone (or an equivalent dose of dexamethasone, hydrocortisone, prednisolone or betamethasone).

\section{Grouping [25]}

All selected children were treated with routine dose of methylprednisolone intravenously within $48-72 \mathrm{~h}$ after admission. According to changes in body temperature, children were divided into conventional dose group and pulse dose group:1) Conventional dose group: after given the initial of methylprednisolone $2 \mathrm{mg} / \mathrm{kg} / \mathrm{day}(<200 \mathrm{mg} /$ day), their body temperature returned to normal within $48 \mathrm{~h}$, their imaging abnormality gradually improved, CRP returned to normal, and there was no recurrence in the process of hormone withdrawal. 2) Pulse therapy: initially given methylprednisolone $2 \mathrm{mg} / \mathrm{kg} /$ day, there was no significant decrease in heat peak within $48 \mathrm{~h}$. Therefore, gradually increased the dose of methylprednisolone. When the dose of methylprednisolone was increased to $200 \mathrm{mg} /$ day or more, their body temperature returned to normal within $48 \mathrm{~h}$. 


\section{Collection of clinical data}

Collect data for each patient, including demographic characteristics, medical history, physical examination results, laboratory data, radiology results, hospital stay, fever time, etc. Record the laboratory data which were detected during hospitalization, including white blood cell (WBC) counts, neutrophil counts, and levels of Creactive protein $(\mathrm{CRP})$, lactate dehydrogenase (LDH), procalcitonin (PCT), alanine aminotransferase (ALT), aspartate aminotransferase (AST), etc [26]. Hypoxia was defined as any oxygen saturation measured by pulse oximetry in indoor air $<92 \%[27,28]$.

\section{Statistical analysis}

Statistical analyses were performed using SPSS software (version 22.0). Normal distribution data were expressed as mean $\pm \mathrm{SD}(\mathrm{x} \pm \mathrm{s})$. Independent-Samples $\mathrm{T}$-test or One-way ANOVA was used to process these data. The skewed distribution data were presented as the median values (P25, P75), and comparisons were made by the Mann-Whitney U-test. Chi-squared tests were used to compare numerical data, which was presented as rate or constituent ratio. Meanwhile, we use the laboratory indicators with significant differences as independent related risk factors to make the ROC curve, and use the area under the ROC curve (AUC) to reflect the accuracy of the diagnostic test. Take the point closest to the upper left corner of the ROC curve, which has the largest sum of sensitivity and specificity, as the optimal value of prediction. The difference was considered statistically significant at $P<0.05$.

\section{Results}

\section{Clinical characteristics}

This study included 125 children. Children were divided into two groups according to GC dose. The age distribution of the subjects was shown in Fig. 1. The 81 patients in group I (36 females, 45 males) had the median age of $6.54 \pm 3.03$ years, and the median weight of $20.4(16.4,28.9)$ $\mathrm{kg}$; The 44 patients in group II (22 females, 22 males) had the median age of $7.61 \pm 2.49$ years, and the median weight of $27.2(20.0,33.5) \mathrm{kg}$, which was shown in Table 1. Gender distribution was not differ between the two groups $(P>0.05)$. There were significant differences between the two groups in the age and weight $(P<0.05, P<0.01)$.

\section{Laboratory findings}

The laboratory values were shown in Table 2 . The median values of Fg, PT, PLT, La, ALT and AST between the two groups were not statistically different $(P>0.05)$. WBC, CRP, LDH, FER, D-dimer, APTT, TT, PCT, IL-6 and the percentage of peripheral neutrophils in group II were higher, with a significant difference $(P<0.05)$.

\section{Imaging findings}

Table 3 summarized the radiological findings in two groups. There were no differences in the incidence of atelectasis and pleural thickening between the two groups $(25.0 \%$ versus $21.0,68.2 \%$ versus $64.2 \%, P>0.05)$. The incidence of pulmonary consolidation $(93.2 \%$ versus $51.9 \%)$ and pleural effusion ( $45.5 \%$ versus $27.2 \%)$ in children with group II were higher than those in group I $(P<0.01, P<0.05)$. Radiological findings were more severe in group II.

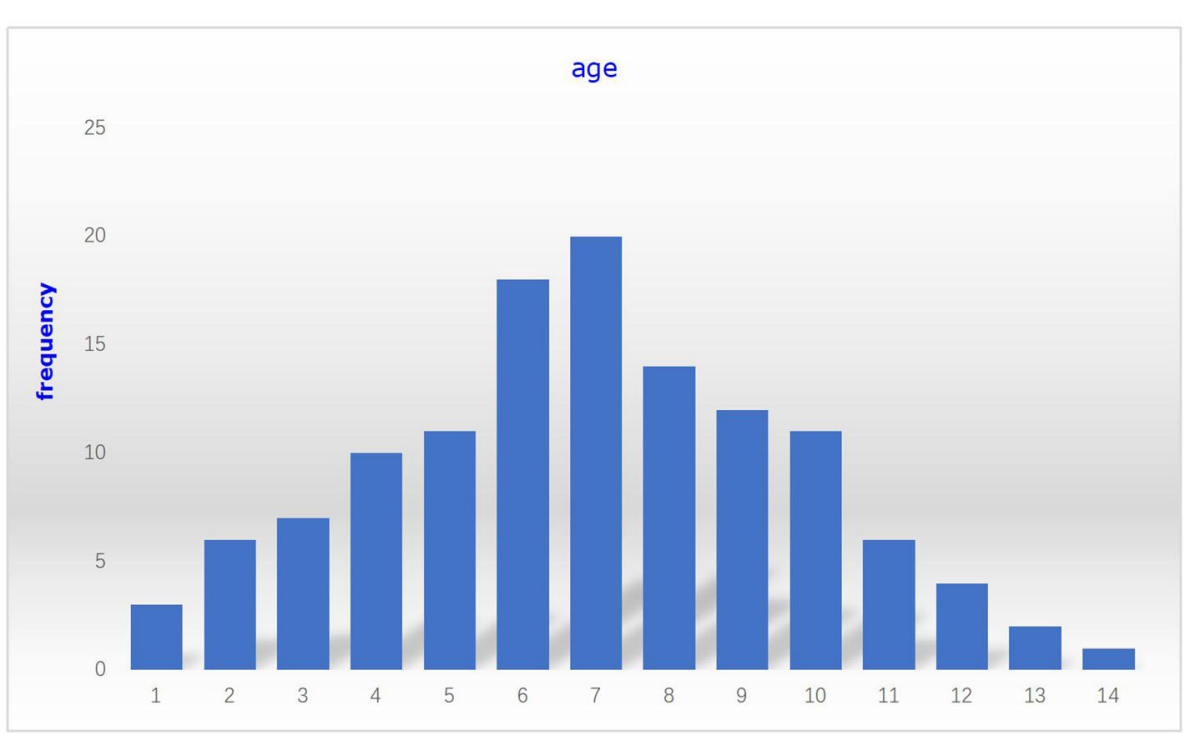

Fig. 1 Age distribution of refractory Mycoplasma pneumoniae pneumonia patients 
Table 1 Clinical characteristic

\begin{tabular}{|c|c|c|c|}
\hline Clinical information & Group I(81) & Group II (44) & $P$-value \\
\hline \multicolumn{4}{|l|}{ General information } \\
\hline Sex (female/male) & $36 / 45$ & $22 / 22$ & 0.552 \\
\hline Age, years & $6.54 \pm 3.03$ & $7.61 \pm 2.49$ & 0.031 \\
\hline Weight, kg & $20.4(16.4,28.9)$ & $27.2(20.0,33.5)$ & 0.002 \\
\hline \multicolumn{4}{|l|}{ Clinical presentation n (\%) } \\
\hline Fever & $81(100 \%)$ & $44(100 \%)$ & 1.00 \\
\hline Cough & 75 (92.6\%) & $43(97.7 \%)$ & 0.891 \\
\hline Hypoxemia & $6(7.41 \%)$ & $28(63.6 \%)$ & 0.000 \\
\hline respiratory failure & 0 & $2(4.55 \%)$ & 0.041 \\
\hline Extra-pulmonary complications & $18(22.2 \%)$ & $33(75.0 \%)$ & 0.007 \\
\hline Thromboembolism & $2(2.47 \%)$ & $2(4.55 \%)$ & 0.613 \\
\hline total fever duration, days & $11(8,13)$ & $13(11,15)$ & 0.000 \\
\hline preadmission fever duration, days & $7(5,8)$ & $6(4,7)$ & 0.329 \\
\hline fever duration at the time of CS treatment ${ }^{a}$, days & $1.95 \pm 1.91$ & $5.45 \pm 2.76$ & 0.000 \\
\hline Length of stay, days & $8(7,10)$ & $13.5(11.3,16)$ & 0.000 \\
\hline \multicolumn{4}{|l|}{ Management } \\
\hline Hormone dose, mg/kg/day & $2(1.5,2)$ & $10(8.5,10)$ & 0.000 \\
\hline Gamma globulin, n (\%) & $9(11.1 \%)$ & $17(38.6 \%)$ & 0.000 \\
\hline Bronchoscopy, n (\%) & $57(70.4 \%)$ & $41(93.2 \%)$ & 0.000 \\
\hline Plastic bronchitis, n (\%) & $14(17.3 \%)$ & $29(65.9 \%)$ & 0.000 \\
\hline
\end{tabular}

Data are presented as number (percentage), median (25th-75th percentile). Data are presented as mean \pm SD $(x \pm s)$

${ }^{a}$ The meaning of fever duration at the time of corticosteroids treatment is that fever days after starting corticosteroids therapy

Table 2 Laboratory characteristic

\begin{tabular}{llll}
\hline Laboratory information & Group I(81) & Group II (44) & $P$-value \\
\hline White blood cell $\left(\times 10^{9} / \mathrm{L}\right)$ & $9.00(7.50,11.2)$ & $11.3(9.20,14.8)$ & 0.001 \\
Neutrophil,\% & $66.0(48.0,73.75)$ & $81.6(76.3,87.0)$ & 0.000 \\
Lymphocytes,\% & $25.5(16.85,40.0)$ & $12.1(8.25,15.0)$ & 0.000 \\
CRP, mg/L & $36.9(12.5,67.2)$ & $69.0(54.0,108)$ & 0.000 \\
LDH,IU/L & $456(345,586)$ & $594(397,776)$ & 0.007 \\
Fer, ng/L & $255(126,345)$ & $543(321,828)$ & 0.000 \\
D-D, mg/L & $0.4(0.2,1.0)$ & $1.15(0.30,3.28)$ & 0.011 \\
Fg, g/l & $3.70(3.31,4.37)$ & $3.84(3.30,4.72)$ & 0.307 \\
PT & $11.9(11.4,12.4)$ & $11.7(11.0,12.3)$ & 0.147 \\
APTT & $30.8(27.8,34.3)$ & $26.4(24.0,30.4)$ & 0.000 \\
TT & $16.3(15.5,17.2)$ & $17.1(16.2,17.8)$ & 0.002 \\
PLT & $338(269,448)$ & $294(225,408)$ & 0.054 \\
PCT, ng/ml & $0.18(0.10,0.37)$ & $0.33(0.17,0.55)$ & 0.007 \\
IL-6,pg/ml & $26.0(14.8,45.9)$ & $46.7(25.1,100.9)$ & 0.001 \\
La, mmol/L & $2.81(2.36,3.36)$ & $2.86(2.35,3.50)$ & 0.781 \\
AST,U/L & $35(27,53)$ & $39(29,53)$ & 0.460 \\
ALT,U/L & $17(12,23)$ & $21(12.3,51)$ & 0.094 \\
\hline
\end{tabular}

Data are presented as median (25th-75th percentile)

WBC White blood cell, Neutrophil Peripheral neutrophils, Lymphocytes

Peripheral Lymphocytes, CRP C-reactive protein, $L D H$ Lactic dehydrogenase,

Fer Ferritin, D-D D-dimer, Fg Fibrinogen, PCT Procalcitonin, IL-6 Interleukin (IL)-

6, La Lactic acid, AST Aspartate aminotransferase, ALT

Alanine aminotransferase

\section{Treatment}

All patients received macrolide therapy. Because the group II had more serious manifestations, higher incidence of extrapulmonary complications and more serious imaging findings, the group II's the usage rate of gamma globulin, the usage rate of bronchoscopy, the incidence of plastic bronchitis were higher than the group I, with a significant difference $(P<0.05, P<0.01, P<0.01)$.

\section{Risk factors for RMPP of pulse dose GC}

The ROC curves shows that CRP, LDH, FER, neutrophil percentage as independent risk factors for children with RMPP treated with pulse dose (Table 4). The cut-off values for CRP, LDH, FER, neutrophil percentage were set at $44.45 \mathrm{mg} / \mathrm{L}, 590 \mathrm{IU} / \mathrm{L}, 411 \mathrm{ng} / \mathrm{L}, 73.75$ respectively.

Table 3 Radiological features

\begin{tabular}{llll}
\hline Radiological features & Group I(81) & Group II (44) & P-value \\
\hline Pulmonary consolidation, n (\%) & $42(51.9 \%)$ & $41(93.2 \%)$ & 0.000 \\
Pleural effusion, n (\%) & $22(27.2 \%)$ & $20(45.5 \%)$ & 0.039 \\
Lobar atelectasis, n (\%) & $17(21.0 \%)$ & $11(25.0 \%)$ & 0.607 \\
Pleural thickening, n (\%) & $52(64.2 \%)$ & $30(68.2 \%)$ & 0.654 \\
\hline
\end{tabular}

Data are presented as number (percentage) 
Table 4 Predictive values of the independent correlation factors

\begin{tabular}{lllllll}
\hline Independent factors & Cutoff value & Sensitivity & Specificity & AUC & P-value & 95\%Cl \\
\hline Neutrophil, \% & 73.75 & 0.750 & 0.900 & 0.888 & 0.000 & $0.831-0.945$ \\
CRP, mg/L & 44.45 & 0.550 & 0.850 & 0.736 & 0.000 & $0.648-0.825$ \\
LDH, IU/L & 590.0 & 0.763 & 0.475 & 0.611 & 0.048 & $0.503-0.719$ \\
Fer, ng/L & 411.0 & 0.864 & 0.682 & 0.814 & 0.000 & $0.736-0.892$ \\
\hline
\end{tabular}

$P$ value: the AUC value of the independent factors compared to ROC curve reference value 0.5

AUC Area under the ROC curve, Cut-off value The value on the ROC curve is closest to the upper right to take maximum sensitivity and specificity

The sensitivity and specificity were respectively $55.0 \%$ \& 85.0, $76.3 \%$ \& $47.5,86.4 \%$ \& 68.2 , and $75.0 \%$ \& 90.0\%.

\section{Discussion}

One of the main pathogens of CAP in children is Mycoplasma pneumoniae. More and more RMPP have been reported [10, 29-33] recently. Studies [34, 35] have shown that more than $90 \%$ of Mycoplasma pneumoniae infections in China are caused by drug-resistant strains. However, the latest research results of Sun et al. [36] have shown that the important cause of MP resistance to macrolide antibiotics was not only related to the irregular use of antibiotics, but also related to the epidemic genotype M4-5-7-2 of Mycoplasma pneumoniae. Through the comparison of genotypes and drug resistance between Chinese, American and Australian strains, it was reasonably explained from a new perspective that the high drug resistance rate in China and even in Asia is not all caused by the abuse of antibiotics, which is closely related to the regional differences in the epidemic genotypes of Mycoplasma pneumoniae [36]. Therefore, macrolides are still used in patients with MP in China. Only when macrolides are ineffective, antibiotics such as tetracyclines or fluoroquinolones can be used according to the condition [37-41]. Due to the influence of the pathogenesis, most of the RMPP will produce complications. The host's excessive immune response plays a key role in the development of RMPP disease [8, 9], such as cytokines (including interleukin-2, interleukin-6 and interleukin-8). Over-expression and highly activated cells (including antigen presenting cells and T cells) mediated immune response etc [42]. GC can be used to downregulate the related cell-mediated immune response and play an effective role in severe cases of MP infection [12-14]. Early control of lung injury caused by overactive immune response by non-specific adaptive immune cells is essential for reducing the incidence of severe MPP and preventing disease progression. Because the severity of RMPP is related to the immune response, and the effect of GC is dose-dependent, higher doses may be needed in patients with severe MPP [4, 43, 44].

A number of studies have revealed that humoral and cellular immune responses $[45,46]$ contribute to the pathogenesis of MP infection, providing a theoretical basis for the application of GC in RMPP. Studies have shown that the addition of GC on the basis of the conventional treatment has a definite effect on RMPP, which contributes to the control of the disease progression, the improvement of the condition and the reduction of sequelae $[10,16]$. So, it is very important to study the application of GC in the treatment of $\operatorname{RMPP}[2,16$, 47].

So, in this retrospective research, 125 patients of RMPP were enrolled. Among them, there were 81 cases in group I, and 44 cases in group II. First of all, this study found that there was a statistical difference in age between group I and group II $(6.54 \pm 3.03,7.61 \pm 2.49$, $P<0.05$ ), which was similar to the previous studies [11, 17]. Children's immune systems gradually mature with age. The more mature of immune system, it is more likely to have a strong inflammatory response to MP and produce too many inflammatory factors, which may lead to the deterioration of RMPP [17].

Secondly, the incidence of hypoxemia, extrapulmonary complications and plastic bronchitis were higher in the group II than those in the group I $(P<$ $0.05)$. Besides, the use rate of oxygen therapy, gamma globulin and bronchoscopy in the group II were high$\operatorname{er}(P<0.05)$. The total fever days, hospital stay, fever days after hormone therapy in group II were significantly higher than in group I $(P<0.05)$. In addition, the study also found that WBC, CRP, LDH, FER, D-D dimer, APTT, TT, PCT, IL-6, ALT and the percentage of neutrophils in peripheral blood in group II were higher than in group I $(P<0.05)$. Finally, the incidence of pulmonary consolidation and pleural effusion were higher in group $\mathrm{II}(P<0.05)$. The imaging findings may be related to the severity of the disease. The difference may is correlation to direct damage and immune inflammatory response [19]. So, if RMPP was not treated effectively, the disease maybe aggravated and the clinical process of disease maybe prolonged.

In order to study the clinical characteristics that can predict the severity of RMPP disease and guide the GC pulsed dose treatment, analyze statistically significant indicators by ROC curve. In ROC curve analysis, CRP, LDH, FER and white blood cell classification of neutrophils were helpful for identifying more severe RMPP 
patients. The optimal cutoff value were $44.45 \mathrm{mg} / \mathrm{L}, 590$ IU/L,411 ng/L and $73.75 \%$, respectively. This study found that CRP $44.45 \mathrm{mg} / \mathrm{L}$, LDH $590 \mathrm{IU} / \mathrm{L}$, FER $411 \mathrm{ng} /$ L, leukocyte classification neutrophil $73.75 \%$, lung consolidation and pleural effusion may be important clinical features of use pulsed dose hormones to treat RMPP.

CRP is the most widely used acute phase inflammatory protein. CRP rises rapidly after inflammation stimulation, which value can reflect the development of the immune system. CRP levels in patients with acute infection, inflammation or trauma may increase in a short time. Chen et al. $[19,21]$. showed that when CRP was $16.5 \mathrm{mg} / \mathrm{L}$ or higher, the sensitivity and specificity for diagnosing MPP with hypoxia were 74.7 and $77.2 \%$, respectively. The cutoffs were less than that in our study. In our study, the optimal cutoff point for CRP was $44.45 \mathrm{mg} / \mathrm{L}$, with a sensitivity of $55 \%$ and specificity of $85 \%$.

LDH is an inflammatory marker. After cell damage, $\mathrm{LDH}$ is released into the serum and can be used to monitor tissue damage in many inflammatory processes. Studies have shown that LDH was related to many lung diseases [48, 49]. Serum LDH was a biomarker of RMPP severity $[1,11,13,19]$. Lu et al. [50].reported that serum LDH can be used as a biomarker for predicting RMPP and evaluating whether to initiate corticosteroid therapy during the initial hospitalization of patients. Chen et al. $[19,21]$. showed that when LDH was $417 \mathrm{IU} / \mathrm{L}$ or higher, the sensitivity and specificity for diagnosing MPP with hypoxia were 79.7 and $65.0 \%$, respectively. In this study, the optimal cutoff for LDH was $590 \mathrm{IU} / \mathrm{L}$, with a sensitivity of $76.3 \%$ and specificity of $47.5 \%$, which was higher than that of previous studies $[13,19]$.

Elevated levels of ferritin may be positively correlated with the severity of inflammation, infection, renal failure and metabolic syndrome. In lung diseases, lung inflammation and tissue damage can lead to increased ferritin levels [51]. Kawamata et al. [12] showed that serum ferritin levels were positively correlated with the severity of children's MPP, and ferritin may be a useful indicator for the initiation of glucocorticoid therapy for MPP. However, there is still no report about the correlation of ferritin in treatment of RMPP with pulse dose of GC. Choi et al. [52] reported that when ferritin was greater than or equal to $230 \mathrm{ng} / \mathrm{mL}$, the sensitivity and specificity for diagnosing RMPP were 67 and $67 \%$. In this study, the area under the curve for ferritin was 0.814 in the ROC curve analysis, which indicates that ferritin has a fair discriminative power in predicting the use of pulse dose to treat RMPP. The optimal cutoff for ferritin was $411 \mathrm{ng} / \mathrm{mL}$, the sensitivity and specificity were 86.4 and $68.2 \%$. The reasons for the difference in the studies are as follows: Firstly, it may be that the research object is RMPP, and the clinical manifestations are more serious; secondly, it may be that the research object contains unrecognized mixed infections.
Systemic GC can be considered for severe MPP with acute onset, rapid progression, especially for RMPP. However, there is no corresponding indicator for the use and timing of hormone dose. There are different opinions on the dosage of hormones in the existing article [11, 16]: You and Lee et al. [42] used intravenous infusion of methylprednisolone $10 \mathrm{mg} / \mathrm{kg} /$ day $\times 3$ days for some patients who had failed oral treatment (dose reduction within 1 week). The clinical manifestations of all patients were significantly improved, and there were no related side effects. Lee [11] et al.treated 15 children with RMPP orally with prednisolone $1 \mathrm{mg} / \mathrm{kg} /$ day, and the dose was reduced after continuous use for 3-7 days, which has a significant therapeutic effect on children with RMPP. Luo et al. proved that oral prednisone (2 $\mathrm{mg} / \mathrm{kg} /$ day) was more effective than azithromycin alone in children with RMPP. And Tamura [2] gave 6 patients with RMPP an intravenous drip of $30 \mathrm{mg} / \mathrm{kg} /$ day $\times 3$ days methylprednisolone. The body temperature of all patients returned to normal within $14 \mathrm{~h}$, and the clinical symptoms were significantly improved. They think that the combined use of hormone therapy can reduce the length of hospital stay and the occurrence of RMPP, and there is no adverse hormone response. The study implied that elder children are prone to more severe presentations, higher incidence of extra-pulmonary complications and more serious imaging. The study suggested that the severity of RMPP was related to host immune response, and the optimal values of CRP, LDH, FER and leukocyte classification neutrophils (CRP44.45 $\mathrm{mg} / \mathrm{L}$, LDH590IU/L, FER411ng/L, leukocyte classification neutrophils $73.75 \%$ ), lung consolidation, and pleural effusion may be the valuable predictors of using methylprednisolone pulse therapy to treat RMPP.

This study indicated that in the treatment of RMPP, timely use of appropriate doses of GC can reduce the intensity of local inflammation, alleviates the immune reaction, and promote disease recovery. During the treatment of RMPP with GC, blood pressure, blood glucose, blood potassium and liver function should be monitored, notice the adverse reactions such as circulatory system and gastrointestinal bleeding, and pay attention to ECG monitoring during pulse dose treatment. And be sure to: (1) the suitable time for treatment; (2)exclude whether there are other infections or lesions; (3prevent the occurrence of double infection.

The study has some limitations. Firstly, retrospective research may have selection bias,which may need large sample, further prospective studies. Second, our hospital is a tertiary hospital with many severely ill patients. The uneven distribution of critically ill patients in this study has a certain impact on the experimental results. Thirdly, the source of patients is relatively single, and the research results may not be ideally suited for patients 
from other sources. To solve this problem, multiregional research is required in the future. Fourth, some patients may be infected with other pathogens, but this pathogen has not been detected, and it may cause the deterioration of RMPP. Finally, the optimal value of risk factor obtained by ROC curve may have some limitations and only guide judgment to a certain extent. More clinical data should be accumulated and further verified in clinical work to obtain more accurate reference standards.

\section{Conclusion}

This research shows that immune inflammatory response may play a vital role in the progression of RMPP. CRP $\geq 44.45 \mathrm{mg} / \mathrm{L}, \quad \mathrm{LDH} \geq 590 \mathrm{IU} / \mathrm{L}, \quad \mathrm{FER} \geq 411$ ng/L, neutrophil $\geq 73.75 \%$, lung consolidation, and pleural effusion may be meaningful predictors that guide the treatment of RMPP with pulse dose of GC, which can reduce the incidence of severe RMPP and the occurrence of severe sequelae.

\section{Abbreviations \\ MP: Mycoplasma Pneumoniae; CAP: Community Acquired Pneumonia; RMPP: Refractory Mycoplasma pneumoniae pneumonia; PCR: Polymerase chain reaction; CRP: C-reactive protein; Fer: Ferritin; D-D: D-dimer Fg: Fibrinogen; LDH: Lactate dehydrogenase; PCT: Procalcitonin; IL: Interleukin; La: Lactic acid; AST: Aspartate aminotransferase; ALT: Alanine aminotransferase; ROC: Receiver operating characteristic}

\section{Acknowledgments}

We owe our thanks to Wei Guo, Yaoyao Ling, and Jiao Tian for their work on revising and data extracting in this manuscript.

\section{Authors' contributions}

Conception and Design: ZLZ, TQZ, and YSX; Extraction of Data: ZLZ, WG, YYL, and JT; Drafting the Article: ZLZ; Revising It for Intellectual Content: ZLZ, and YSX; Final Approval of the Completed Article: ZLZ, TQZ, and YSX. All authors read and approved the final manuscript.

\section{Funding}

Rapid molecular diagnosis of pathogens in children's respiratory infectious diseases and precise treatment with antibiotics (20JCZXJC00170). The funding body had no role in the design of the study and collection, analysis, and interpretation of data and in writing the manuscript.

\section{Availability of data and materials}

The datasets used and/or analyzed during the current study are available from the corresponding author on reasonable request.

\section{Ethics approval and consent to participate}

All procedures performed in studies involving human participants were following the Ethics Committee of Tianjin Children's Hospital (Approved No. of ethic committee: L2021-01). The ethics committee waived the need for written informed consent provided by participants due to the retrospective nature of the study, because all patient data were analyzed anonymously, and no additional informed consent was required.

\section{Consent for publication}

Not applicable.

\section{Competing interests}

The authors declare no conflict of interest.

\section{Author details}

'Tianjin Medical University, Tianjin Children's Hospital (Children's Hospital of Tianjin University), No.22, Qixiangtai Road, Heping District, Tianjin 300070, China. ${ }^{2}$ Department of Respiratory, Tianjin Children's Hospital (Children's Hospital of Tianjin University), Tianjin, People's Republic of China. ${ }^{3}$ Department of Pediatrics, Graduate School of Tianjin Medical University, Tianjin 300074, People's Republic of China. ${ }^{4}$ Department of Respiratory, The Children's Hospital of Tianjin (Children's Hospital of Tianjin University), Tianjin 300074, China

Received: 10 August 2020 Accepted: 22 January 2021

Published online: 28 January 2021

\section{References}

1. Liu JR, Peng Y, Yang HM, Li HM, Zhao SY, Jiang ZF. Clinical characteristics and predictive factors of refractory mycoplasma pneumoniae pneumonia. Zhonghua Er Ke Za Zhi. 2012;50(12):915-8.

2. Tamura A, Matsubara K, Tanaka T, Nigami H, Yura K, Fukaya T. Methylprednisolone pulse therapy for refractory mycoplasma pneumoniae pneumonia in children. J Inf Secur. 2008;57(3):223-8.

3. Wang J, Yang Y, Zhao SY. Bronchitis obliterans in children: report of two cases and literature review. Zhonghua Er Ke Za Zhi. 2010;48(10):764-6.

4. Sun LL, Ye C, Zhou YL, Zuo SR, Deng ZZ, Wang CJ. Meta-analysis of the clinical efficacy and safety of high- and low-dose methylprednisolone in the treatment of children with severe mycoplasma Pneumoniae pneumonia. Pediatr Infect Dis J. 2020;39(3):177-83.

5. Yan C, Xue G, Zhao H, et al. Molecular and clinical characteristics of severe mycoplasma pneumoniae pneumonia in children. Pediatr Pulmonol. 2019; 54(7):1012-21.

6. Garcia AV, Fingeret AL, Thirumoorthi AS, Kadenhe-Chiweshe A, Kandel JJ. Severe mycoplasma pneumoniae infection requiring extracorporeal membrane oxygenation with concomitant ischemic stroke in a child. Pediatr Pulmonol. 2013:48(1):98-101.

7. Park IH, Choi DY, Oh YK, Kim JD, Yu ST. A case of acute myopericarditis associated with mycoplasma pneumoniae infection in a child. Korean Circ J. 2012;42(10):709-13.

8. Yu JL, Song QF, Xie ZW, et al. iTRAQ-based quantitative proteomics study in patients with refractory mycoplasma pneumoniae pneumonia. Jpn J Infect Dis. 2017;70(5):571-8.

9. Waites KB, Balish MF, Atkinson TP. New insights into the pathogenesis and detection of mycoplasma pneumoniae infections. Future Microbiol. 2008; 3(6):635-48.

10. Luo Z, Luo J, Liu E, et al. Effects of prednisolone on refractory mycoplasma pneumoniae pneumonia in children. Pediatr Pulmonol. 2014:49(4):377-80.

11. Lee KY, Lee HS, Hong JH, et al. Role of prednisolone treatment in severe mycoplasma pneumoniae pneumonia in children. Pediatr Pulmonol. 2006; 41(3):263-8.

12. Kawamata R, Yokoyama K, Sato M, Goto M, Nozaki Y, Takagi T, Kumagai H, Yamagata TJ. Infect Chemother. 2015;21:783-9.

13. Inamura N, Miyashita N, Hasegawa S, et al. Management of refractory mycoplasma pneumoniae pneumonia: utility of measuring serum lactate dehydrogenase level. J Infect Chemother. 2014;20(4):270-3.

14. Remmelts HH, Meijvis SC, Biesma DH, et al. Dexamethasone downregulates the systemic cytokine response in patients with community-acquired pneumonia. Clin Vaccine Immunol. 2012;19(9):1532-8.

15. Tagliabue C, Salvatore CM, Techasaensiri C, et al. The impact of steroids given with macrolide therapy on experimental mycoplasma pneumoniae respiratory infection. J Infect Dis. 2008;198(8):1180-8.

16. Lu A, Wang L, Zhang $X$, Zhang M. Combined treatment for child refractory mycoplasma pneumoniae pneumonia with ciprofloxacin and glucocorticoid. Pediatr Pulmonol. 2011;46(11):1093-7.

17. Wang M, Wang Y, Yan Y, Zhu C, Huang L, Shao X, Xu J, Zhu H, Sun X, Ji W, Chen Z. Int J Infect Dis. 2014;29:18-23.

18. Lee SC, Youn YS, Rhim JW, Kang JH, Lee KY. Early serologic diagnosis of mycoplasma pneumoniae pneumonia: an observational study on changes in titers of specific-lgM antibodies and cold agglutinins. Medicine (Baltimore). 2016;95(19):e3605.

19. Zhang Y, Zhou Y, Li S, Yang D, Wu X, Chen Z. PLoS One. 2016;11:e0156465.

20. Subspecialty Group of Respiratory Diseases. The Society of Pediatrics; Chinese Medical Association the editorial board, Chinese journal of pediatrics. Zhonghua Er Ke Za Zhi. 2013;51:856-62. 
21. Ling Y, Zhang T, Guo W, Zhu Z, Tian J, Cai C, Xu Y. BMC Infect Dis. 2020;20: 534.

22. Lamontagne F, Briel M, Guyatt GH, Cook DJ, Bhatnagar N, Meade M. Corticosteroid therapy for acute lung injury, acute respiratory distress syndrome, and severe pneumonia: a meta-analysis of randomized controlled trials. J Crit Care. 2010;25(3):420-35.

23. Tang BM, Craig JC, Eslick GD, Seppelt I, McLean AS. Use of corticosteroids in acute lung injury and acute respiratory distress syndrome: a systematic review and meta-analysis. Crit Care Med. 2009;37(5):1594-603.

24. Buttgereit F, da Silva JA, Boers M, et al. Standardised nomenclature for glucocorticoid dosages and glucocorticoid treatment regimens: current questions and tentative answers in rheumatology. Ann Rheum Dis. 2002; 61(8):718-22.

25. $L I C, J R L$, Sy Z, et al. The clinical features and treatment of children with refractory mycoplasma pneumoniae pneumonia who have failed to treat with conventional doses of methylprednisolone. Zhonghua Er Ke Za Zhi. 2014;52(03):172-6.

26. Zhou Y, Zhang Y, Sheng $Y$, et al. More complications occur in macrolideresistant than in macrolide-sensitive mycoplasma pneumoniae pneumonia. Antimicrob Agents Chemother. 2014;58(2):1034-8.

27. Tan TQ, Mason EO Jr, Wald ER, et al. Clinical characteristics of children with complicated pneumonia caused by Streptococcus pneumoniae. Pediatrics. 2002;110(1 Pt 1):1-6.

28. Izumikawa K, Izumikawa K, Takazono T, et al. Clinical features, risk factors and treatment of fulminant mycoplasma pneumoniae pneumonia: a review of the Japanese literature. J Infect Chemother. 2014;20(3):181-5.

29. Kim CK, Kim SW, Kim JS, et al. Bronchiolitis obliterans in the 1990s in Korea and the United States. Chest. 2001;120(4):1101-6.

30. Wang RS, Wang SY, Hsieh KS, et al. Necrotizing pneumonitis caused by mycoplasma pneumoniae in pediatric patients: report of five cases and review of literature. Pediatr Infect Dis J. 2004;23(6):564-7.

31. Azumagawa K, Kambara Y, Murata T, Tamai H. Four cases of arthritis associated with mycoplasma pneumoniae infection. Pediatr Int. 2008;50(4): $511-3$.

32. Hawkins S, Rausch CM, McCanta AC. Constrictive pericarditis secondary to infection with mycoplasma pneumoniae. Curr Opin Pediatr. 2011;23(1):126-9.

33. Khan FY. A yM. Mycoplasma pneumoniae associated with severe autoimmune hemolytic anemia: case report and literature review. Braz $\rfloor$ Infect Dis. 2009;13(1):77-9.

34. Liu Y, Ye X, Zhang H, et al. Antimicrobial susceptibility of mycoplasma pneumoniae isolates and molecular analysis of macrolide-resistant strains from Shanghai, China. Antimicrob Agents Chemother. 2009;53(5):2160-2.

35. Zhou Z, Li X, Chen X, et al. Macrolide-resistant mycoplasma pneumoniae in adults in Zhejiang, China. Antimicrob Agents Chemother. 2015;59(2):1048-51.

36. Sun $\mathrm{H}$, Xue G, Yan $\mathrm{C}$, et al. Changes in molecular characteristics of mycoplasma pneumoniae in clinical specimens from children in Beijing between 2003 and 2015. PLoS One. 2017;12(1):e0170253.

37. Kawai Y, Miyashita N, Kubo M, et al. Therapeutic efficacy of macrolides, minocycline, and tosufloxacin against macrolide-resistant mycoplasma pneumoniae pneumonia in pediatric patients. Antimicrob Agents Chemother. 2013;57(5):2252-8.

38. Kawai Y, Miyashita N, Yamaguchi T, et al. Clinical efficacy of macrolide antibiotics against genetically determined macrolide-resistant mycoplasma pneumoniae pneumonia in paediatric patients. Respirology. 2012;17(2):354-62.

39. Ishiguro N, Koseki N, Kaiho M, et al. Therapeutic efficacy of azithromycin, clarithromycin, minocycline and tosufloxacin against macrolide-resistant and macrolide-sensitive mycoplasma pneumoniae pneumonia in pediatric patients. PLoS One. 2017;12(3):e0173635

40. The Subspecialty Group of Respiratory Disease, The Society of Pediatrics, Chinese Medical Association, The Editorial Board, Chinese Journal of Pediatrics. Guidelines for management of community acquired pneumonia in children (the revised edition of 2013) (I). Chin J Pediatr. 2013;51(10):745-9.

41. Zhou Y, Wang J, Chen W, et al. Impact of viral coinfection and macrolideresistant mycoplasma infection in children with refractory mycoplasma pneumoniae pneumonia. BMC Infect Dis. 2020;20(1):633.

42. Youn Y, Lee K. Mycoplasma pneumoniae pneumonia in children. Korean J Pediatr. 2012;55(2):42-7.

43. Lee KY. Pneumonia, Acute Respiratory Distress Syndrome, and Early Immune-Modulator Therapy. Int J Mol Sci. 2017;18(2).

44. Lee KY, Rhim JW, Kang JH. Immunopathogenesis of COVID-19 and early immunomodulators. Clin Exp Pediatr. 2020;63(7):239-50.
45. Kim NH, Lee JA, Eun BW, et al. Comparison of polymerase chain reaction and the indirect particle agglutination antibody test for the diagnosis of mycoplasma pneumoniae pneumonia in children during two outbreaks. Pediatr Infect Dis J. 2007;26(10):897-903.

46. Attilakos A, Palaiologou P, Lagona E, Voutsioti A, Dinopoulos A. Mycoplasma pneumoniae encephalopathy: recovery after intravenous immunoglobulin. Pediatr Neurol. 2008;38(5):357-9.

47. Chen L, Liu J, Zhao S, Yang Y, Wu J. Clinical features and treatment of refractory mycoplasma pneumoniae pneumonia unresponded to conventional dose methylprednisolone in children. Zhonghua Er Ke Za Zhi. 2014:52(3):172-6.

48. Drent M, Cobben NA, Henderson RF, Wouters EF, van Dieijen-Visser M. Usefulness of lactate dehydrogenase and its isoenzymes as indicators of lung damage or inflammation. Eur Respir J. 1996;9(8):1736-42.

49. Nakajima M, Kawahara Y, Yoshida K, Miyashita N, Niki Y, Matsushima T. Serum KL-6 as a possible marker for amiodarone-induced pulmonary toxicity. Intern Med. 2000;39(12):1097-100.

50. Lu A, Wang C, Zhang X, Wang L, Qian L. Respir Care. 2015;60:1469-75.

51. Isoda K, Takeuchi T, Kotani T, Hata K, Shoda T, Ishida T, Yoshida S, Kimura Y, Makino S, Hanafusa T. PLoS One. 2014;9:e89610.

52. Choi YJ, Jeon JH, Oh JW. Critical combination of initial markers for predicting refractory mycoplasma pneumoniae pneumonia in children: a case control study. Respir Res. 2019;20(1):193.

\section{Publisher's Note}

Springer Nature remains neutral with regard to jurisdictional claims in published maps and institutional affiliations.

\section{Ready to submit your research? Choose BMC and benefit from:}

- fast, convenient online submission

- thorough peer review by experienced researchers in your field

- rapid publication on acceptance

- support for research data, including large and complex data types

- gold Open Access which fosters wider collaboration and increased citations

- maximum visibility for your research: over $100 \mathrm{M}$ website views per year

At BMC, research is always in progress.

Learn more biomedcentral.com/submissions 